\title{
ORGANISMOS INTERNACIONAIS: os discursos cepalinos e o fetiche tecnológico ${ }^{1}$
}

Andréa Villela Mafra da Silva²

Resumo: Este artigo trata das práticas discursivas da Comissão Econômica para a América Latina e o Caribe (CEPAL), no campo das políticas educacionais. Busco evidenciar os diferentes sentidos atribuídos às tecnologias da informação e comunicação nos documentos cepalinos, utilizando como referencial teórico e metodológico a Análise Crítica do Discurso, formulada por Norman Fairclough. Concluo que o discurso da CEPAL pode ser considerado tanto como uma espécie de receituário quanto justificativa para divulgar avaliações e diagnósticos sobre os resultados das reformas educacionais implementadas na América Latina e Caribe. Palavras-chave: Organismos Internacionais. Análise Crítica do Discurso. Políticas Educacionais.

Abstract: This article reflects about the discursive practices of the Economic Commission for Latin America and Caribbean (CEPAL), on the field of educational policies. Intends to highlight the different senses given to the information and communication technologies on cepalinos documents, using as theoretical and methodological reference the Critical Discourse Analysis, developed by Norman Fairclough. It concludes that the CEPAL's discourse can be considered both such as some kind of recipe and justification to advertise evaluations and diagnoses about the results of the educational reforms implanted in Latin America and Caribbean.

Keywords: International Organisms. Critical Discourse Analysis. Educational Policies.

\section{Introdução}

O marco na história da criação dos organismos internacionais foi a Segunda Guerra Mundial, ocasião em que, especificamente, os Estados Unidos da América do Norte, prestou assistência aos países destruídos na Guerra. Por definição Organismos Internacionais são associações de no mínimo três Estados Nacionais denominados como países membros, que "não se limitam a desempenhar as tarefas próprias de simples agências de crédito", mas exercem

\footnotetext{
1DOI: https://doi.org/10.22409/tn.15i27.p9637

${ }^{2}$ Doutoranda no ProPEd/UERJ. Professora do Ensino Superior da FAETEC. E-mail: av.mafra@hotmail.com
}

TrabalhoNecessario - www.uff.br/trabalhonecessario; Ano 15, № 27/2017 
"função político-estratégica fundamental nos processos de ajuste e reestruturação neoliberal" (GENTILI, 2001, p. 29).

A atuação desses organismos é basicamente fornecer empréstimos aos países periféricos ${ }^{2}$ e atuar no controle econômico, cultural e político estabelecendo o cumprimento de condicionalidades, que expressam as suas intervenções na definição das políticas dos países periféricos. Tomo o conceito de condicionalidade elaborado por Leher (1999) como o processo pelo qual os empréstimos financeiros concedidos pelos organismos internacionais estão condicionados à implementação de reformas na política macroeconômica e nas políticas setoriais à luz do projeto societário do capital.

Os programas dos organismos podem ser classificados em quatro segmentos: (1) Cooperação, tais como a Organização das Nações Unidas para a Educação, a Ciência e a Cultura (UNESCO) e a Organização dos Estados Americanos (OEA); (2) Financiamento, como o Banco Internacional para Reconstrução e Desenvolvimento (BIRD) e Banco Interamericano de Desenvolvimento (BID); (3) Normativo, tais como Acordo Geral sobre Tarifas e Comércio (GATT) e Organização Mundial para a Propriedade Intelectual (OMPI); e (4) Político como a Assembleia Geral das Nações Unidas (AGNU) e a Organização dos Estados Americanos (OEA).

Os Organismos Internacionais, em suas prescrições nas políticas educacionais, evidenciam propostas feitas basicamente a partir de uma lógica econômica em que a relação custo-benefício norteia as prioridades de investimento no campo. Vários autores têm pensado criticamente as formas de atuação dos organismos internacionais (LEHER, 1999a, 1999b; BARRETO, 2009; BARRETO, LEHER, 2008; LIMA, 2001, 2003; SGUISSARDI, 2006; KRUPPA, 2000) e suas interferências na definição das políticas educacionais

A história da política educacional brasileira está marcada pelas ações dos organismos internacionais, particularmente, nas reformas educacionais realizadas

\footnotetext{
2 Para a teoria da dependência a caracterização dos países decorre da relação do capitalismo mundial de dependência entre países centrais e países periféricos. Países centrais, como centro da economia mundial. A expressão países periféricos se refere aos espaços onde o desenvolvimento da ciência, da técnica e da informação ocorre em menor escala. Fonte: BAPTISTA FILHO, Almir Cezar de Carvalho. Dinâmica, determinações e sistema mundial no desenvolvimento do capitalismo nos termos de Theotônio dos Santos: da Teoria da Dependência à Teoria dos Sistemas-mundo. Dissertação de Mestrado apresentada como ao Programa de PósGraduação em Economia da Universidade Federal de Uberlândia, 2009.
} 
nos anos 1990. Expressões como "sociedade do conhecimento", "economia baseada no conhecimento", "democratização", "aprendizagem ao longo da vida" ganharam representatividade nos discursos oficiais dos organismos internacionais. Fairclough (2006) afirma que o discurso da Economia Baseada no Conhecimento utilizado pelos organismos representa processos e tendências que, de alguma forma, contribuem para sustentar estratégias para sua propagação ao redor do mundo. Noutras palavras, na análise faircloughiana o processo de legitimação do discurso, como relações de dominação podem ser sustentadas pelo menos por três estratégias: a racionalização (através de um conjunto de relações sociais); a universalização (baseada na ideia de que se servem aos interesses de alguns indivíduos servem ao interesse do coletivo); e a narrativização (como estratégia de legitimação do discurso).

\section{Comissão Econômica para a América Latina e o Caribe (CEPAL): Os discursos cepalinos e o fetiche tecnológico}

Com sede em Santiago do Chile, a Comissão Econômica para a América Latina e o Caribe (CEPAL) criada em 1948 pelo Conselho Econômico e Social das Nações Unidas tem como objetivo coordenar e acompanhar as políticas direcionadas à promoção do desenvolvimento econômico dos países latinoamericanos e reforçar as relações econômicas desses países entre si e com as demais nações do mundo. Suas propostas de caráter reformista, surgiram no contexto de uma economia mundial em crise, sobretudo com o colapso produtivo na Europa que se intensificou durante a Segunda Guerra Mundial.

Os dois principais documentos que servem de base ao pensamento cepalino são: (a) O desenvolvimento econômico da América Latina e alguns de seus problemas principais, publicado em 1949, de autoria de Raúl Prebisch ${ }^{3}$ (1901-1986), único economista latino-americano que se tornaria secretário-

\footnotetext{
${ }^{3}$ Raúl Prebisch teve reconhecimento internacional com indicação ao primeiro Prêmio Nobel de Economia. Em 1982, Prebisch publicou a obra Cinco etapas de mi pensamiento sobre el desarrollo em que relata as etapas do desenvolvimento econômico. Ao estudar o pensamento de Raúl Prebisch, estamos tratando da realidade brasileira do "desenvolvimentismo" após a crise dos anos 1930, chegando até os problemas da dívida externa e da hiperinflação dos anos 1980. O Brasil foi um dos principais países que sofreram a influência das ideias de Prebisch. Fonte: < http://www.scielo.br/pdf/ecos/v16n1/a03v16n1.pdf> Acesso em 23 nov. 2016.
} 
executivo da CEPAL, em meados da década de 1950; (b) Estudo econômico da América Latina-1949, datado de 1951. Os dois documentos são reconhecidos como a doutrina Prebisch-CEPAL.

Na década de 1970, a CEPAL foi criticada por inconsistências em sua concepção de subdesenvolvimento e pelo seu conjunto de políticas, que tinham como objetivo à superação do subdesenvolvimento e da pobreza, pela via da industrialização. As críticas endereçadas ao discurso cepalino parte de dois argumentos fundamentais. O primeiro argumento, se refere a análise estruturalista, característica do pensamento cepalino, que negligencia a influência da formação institucional dos países latino-americanos sobre seu desenvolvimento econômico considerando irreversível sua posição periférica no comércio internacional (NORTH, 1991). O segundo argumento, parte da noção de dependência, utilizada tanto por autores cepalinos quanto marxistas e outros vinculados ao estruturalismo. Trata-se de pressupor uma relação de dominação econômica e política imposta pelas economias centrais, e que, portanto, não tem origem em qualquer tipo de característica peculiar das economias periféricas (idem).

De modo geral, as formulações cepalinas apresentam a ideia da "incorporação e difusão do progresso técnico como fator fundamental para que a região desenvolva uma competitividade autêntica que lhe permita se inserir com êxito na economia mundial" (CEPAL, 1990, p. 10). Dessa perspectiva sustentada pela CEPAL a incorporação do progresso técnico advém de um conjunto de fatores como o fortalecimento da base empresarial, da infraestrutura tecnológica, da crescente abertura à economia internacional e, principalmente, da formação de recursos humanos que favoreçam o acesso e a geração de novos conhecimentos (idem).

No contexto dessas orientações, inscrevem-se as reformas educativas e a naturalização de um receituário único, que independe das condições objetivas dos países envolvidos. Mais especificamente, a Cepal defende o argumento de que há uma crise na Educação intensificada pela ausência de articulação com setores da vida social, política, econômica e cultural (CEPAL, 1990).

A despeito de não ser exatamente uma instituição preocupada com política educacional, as orientações cepalinas perpassam pelo entendimento de que a Educação é responsável pela elevação do patamar de competitividade 
internacional entre os países frente às diversas transformações sucedidas na economia ao nível global (BIESLCHOWSKY, 2000). Assim, para a CEPAL "a reforma do sistema de produção e difusão do conhecimento constitui, pois, instrumento fundamental para enfrentar tanto os desafios internos - ligados à consolidação da cidadania - como externos - relativos à competitividade" (CEPAL, 1995, p.8).

Tenho entendido que o volume de documentos produzidos pela CEPAL pode ser considerado tanto como uma espécie de receituários quanto justificativas para divulgar avaliações e diagnósticos sobre os resultados das reformas educacionais implementadas na América Latina e Caribe. A lógica argumentativa que sustenta os documentos cepalinos produzem efeitos de verdade criados pelo discurso estatístico (Fairclough, 2001, p. 91), que por sua vez contribuem "para a constituição de todas as dimensões da estrutura social que, direta ou indiretamente, o moldam e o restringem" (idem).

Fairclough (2001, p. 105) demonstra que os significados e sentidos com que as palavras são empregadas "entram em disputas dentro de lutas mais amplas", uma vez que, "as estruturações particulares das relações entre as palavras e das relações entre os sentidos de uma palavra são formas de hegemonia". O conceito de hegemonia da teoria do discurso, tal como elaborada por Fairclough:

é liderança tanto quanto dominação nos domínios econômico, político, cultural e ideológico de uma sociedade. Hegemonia é poder sobre a sociedade como um todo de uma das classes economicamente definidas como fundamentais em aliança com outras forças sociais, mas nunca atingido senão parcial e temporariamente, como um 'equilíbrio instável'. Hegemonia é a construção de alianças e a integração muito mais do que simplesmente a dominação de classes subalternas, mediante concessões ou meios ideológicos para ganhar seu consentimento (FAIRCLOUGH, 2001, p. 122).

Desse modo, os discursos hegemônicos reorganizam as relações sociais de um contexto sócio histórico específico. A recomendação central da publicação Invertir mejor para invertir más: Financiamiento y Gestión de la Educación en América Latina y el Caribe (2005) preparado pela Divisão de Desenvolvimento Social da CEPAL, em conjunto com a Organização das Nações Unidas para a Educação, a Ciência e a Cultura (UNESCO), apresenta como um dos objetivos a 
abordagem dos principais desafios de financiamento e de gestão dos sistemas educacionais dos países no século XXI.

$\mathrm{Na}$ seção do documento que trata dos investimentos em Educação e do alcance de bons resultados das reformas educativas é destacado a necessidade de: (a) orientar a gestão institucional, a serviço da aprendizagem; (b) promover maior responsabilidade social pela Educação; (c) promover melhores condições de trabalho aos professores (CEPAL, 2005).

Os fóruns são veículos difusores das ideias cepalinas. O Fórum sobre os Benefícios da Digitalização da Educação na América Latina, ocorreu no Estado de São Paulo, no dia 19 de maio de 20164. O evento contou com a participação de representantes de organizações não-governamentais, representantes da indústria, legisladores, e outros membros do governo envolvidos em questões políticas relacionadas à tecnologia da informação, telecomunicações e finanças. Neste evento foram tomadas as primeiras resoluções sobre o papel da conectividade e tecnologia na educação e nos processos educativos. O objetivo é "melhorar e transformar a qualidade da educação na América Latina, proporcionar conectividade à internet em toda sala de aula e digitalizar a educação" (CEPAL, 2016).

Evento similar foi promovido pela CEPAL com o mesmo fio condutor Programa de Conectividade do Século XXI - que analisou o papel das TIC na conectividade de banda larga das salas de aula, com o intuito de estabelecer um conjunto de metas voltadas para a educação digital. Os trechos, a seguir, retirados do programa indicam as TIC como solução e parte indispensável para os problemas educacionais:

As TICs (Information and communication technologies, Tecnologias de informação e comunicação) não são mais meras ferramentas práticas de interação. Elas evoluíram e se tornaram parte indispensável de tudo, de operações governamentais a processos de negócios e atividades individuais (CEPAL, 2015, p. 5) (grifo meu).

Em um mundo cada vez mais conectado, ficar abaixo da curva de adoção da tecnologia apresenta uma grande desvantagem. Essa relação é mais facilmente percebida no setor da educação. A educação abre portas e oferece oportunidades para sair da

${ }^{4}$ C.f.<http://www.segs.com.br/info-ti/17541-caf-cepal-e-cisco-juntam-esforcos-para-digitalizar-aeducacao-na-america-latina.html> Acesso em 23 nov. 2016

TrabalhoNecessario - www.uff.br/trabalhonecessario; Ano 15, № 27/2017 
pobreza. Com os recursos adequados, os alunos têm chance de melhorar sua formação, a vida pessoal e profissional. Ainda assim, à medida que as tecnologias educativas evoluem, apenas aqueles que podem acessá-las são beneficiados, aumentando a distância entre o progresso e a estagnação econômica (CEPAL, 2015, p. 5).

Para garantir que todos colham os benefícios das TICs, é necessário ampliar a disponibilidade e a adoção da banda larga, principalmente por meio de políticas que conectem escolas, todas as salas de aula e bibliotecas a serviços de internet de banda larga (CEPAL, 2015, p. 5).

O argumento que as TIC "evoluíram e se tornaram parte indispensável de tudo" (caracterizado como argumento principal do programa) envolve o desconhecimento as restrições da aplicação prática desse enunciado. A despeito, da ausência de condições objetivas de trabalho do professor, para 0 aproveitamento das TIC na Educação e também da falta de política de formação de professores direcionadas para o aproveitamento das tecnologias de informação e comunicação - o discurso dominante tem em seus princípios a ideia de que as TIC garantem avanço e mudança no processo de ensino e aprendizagem.

O que me parece fundamental pontuar que esses supostos estão também presentes em outro documento da CEPAL - Agenda digital para América Latina y el Caribe - publicado um ano antes, precisamente em 2015. Conforme sugere Fairclough (2001) é fundamental analisar pistas em diferentes textos para identificar a forma como os discursos são construídos e capazes de reestruturar as práticas sociais. Um dos mecanismos de construção simbólica nos eventos discursivos se refere a narrativização, isto é, a apropriação de outros textos como uma estratégia de legitimação do discurso em busca do processo de consenso (FAIRCLOUGH, 2003). Para ilustrar, cito o excerto do documento da CEPAL (2015) já referido, que assim como as outras publicações deste organismo insistem na ideia salvacionista das TIC:

A medida que las TIC, y en especial Internet, permean todos los ámbitos económicos y sociales, su relevancia en términos de innovación, crecimiento y desarrollo adquiere una nueva dimensión. Luego de más de una década de políticas sobre TIC, América Latina y el Caribe muestra avances en el establecimiento de marcos jurídicos, los niveles de cobertura de los servicios de telecomunicaciones (telefonía móvil e Internet, principalmente), la 
implementación de programas en los ámbitos sociales (en especial, educación y salud) y el desarrollo del gobierno electrónico. No obstante, los países de la región continúan avanzando a velocidades distintas, con brechas dentro de ellos y entre ellos, así como diferencias frente a las economías más desarrolladas (CEPAL, 2015, p.02).

La propuesta de agenda digital para América Latina y el Caribe (eLAC2018) se plantea como misión desarrollar un ecosistema digital en América Latina y el Caribe que, mediante un proceso de integración y cooperación regional, fortalezca las políticas que impulsen una sociedad basada en el conocimiento, la inclusión y la equidad, la innovación y la sostenibilidad ambiental (CEPAL, 2015, p.03).

Incorporar o fortalecer el uso de las TIC en la educación y promover el desarrollo de programas que contemplen la capacitación de docentes, nuevos modelos pedagógicos, la generación, adaptación e intercambio de recursos educativos abiertos, la gestión de las instituciones de educación y evaluaciones educativas (CEPAL, 2015, p. 05).

Conforme tenho argumentado, emanam das posições cepalinas a ênfase na introdução das TIC nas práticas pedagógicas nas escolas como recursos que permitem experimentar processos de inovação curricular e o estabelecimento de ambientes de aprendizagem dinâmicos e eficazes. Leher (2010b) em sua crítica ao determinismo tecnológico das políticas educacionais, influenciadas pelos Organismos Internacionais, indaga: como é que a tecnologia pode ser sujeito se ela é a relação de produção, é a relação social?

A estes fatores, acrescento que os discursos cepalinos têm em seus princípios a tendência ao fetiche tecnológico. Essa ideia se materializa na tendência cepalina em frisar a promoção de políticas educacionais para o uso intensivo das TIC: "Impulsar la medición del acceso y uso de las TIC, a nivel nacional y regional, fortaleciendo los marcos institucionales necesarios para la articulación, monitoreo, medición y promoción de las políticas en materia digital" (CEPAL, 2015, p.06).

\section{Análise Crítica do Discurso: a abordagem faircloughiana}

Norman Fairclough, linguista britânico, é professor Emérito da Universidade de Lancaster na Grã-Bretanha. Fairclough é reconhecido pela sua significativa 
contribuição ao estabelecer um quadro metodológico que permite investigar a relação entre o discurso e a mudança social. A teoria de Fairclough se propõe a analisar o papel da linguagem e outros elementos semióticos, tais como imagens, na reprodução das práticas sociais e das ideologias.

Em sua obra intitulada Language and power, Fairclough faz uma das primeiras abordagens à análise crítica do discurso, focando "a linguagem na produção, manutenção e mudança das relações sociais de poder" (FAIRCLOUGH, 1989, p. 01). A Análise Crítica do Discurso se preocupa, especialmente, com as mudanças radicais na vida social contemporânea e com as práticas de produção de linguagem, dentro das quais a vida social é produzida, seja esta econômica, política ou cultural. Toda prática de produção de linguagem inclui os seguintes elementos: (a) a atividade produtiva; (b) os meios de produção; (c) as relações sociais; (d) as identidades sociais; (e) os valores culturais; dentre outros (FAIRCLOUGH, 1989).

A linguagem enquanto discurso, pressupõe não só analisar textos e processos de produção e de interpretação, mas também analisar as relações entre estes (textos) e as condições das estruturas sociais. Nesse sentido, apoiada no arcabouço teórico-analítico da Análise Crítica do Discurso (FAIRCLOUGH, 2006), busco compreender as diferentes práticas discursivas associadas às mudanças da prática social.

Busco evidenciar os diferentes sentidos atribuídos às TIC nas políticas educacionais, com base na análise das dimensões semântica (ressignificações e relexicalizações que remetem à reconfiguração dos processos de formação e trabalho docente), sintática (as TIC como agentes das mudanças propostas nas formulações das políticas educacionais) e pragmática (a recorrência do discurso salvacionista das TIC) do corpus.

$\mathrm{Na}$ concepção da análise crítica do discurso, a linguagem deve ser empiricamente analisada a partir do seu contexto social. Isto significa que todos os discursos são históricos e sempre calcados em análises concretas e linguísticas do uso da linguagem em práticas sociais. Na linguística, a noção de discurso é utilizada como referência a amostras ampliadas de linguagem falada ou escrita. $O$ texto é considerado como uma dimensão do discurso que pode representar, constituir, posicionar e construir os indivíduos de diversas maneiras, como sujeitos sociais. 
Historicamente, os discursos se combinam ou se modificam em condições sociais produzindo um novo discurso. Em última análise, discurso se refere a diferentes tipos de linguagem utilizada em diferentes tipos de situações sociais, como o discurso de sala de aula, o discurso da mídia ou o discurso da ciência médica.

A escolha de Norman Fairclough no processo de análise do discurso das políticas justifica-se pela possibilidade de focalizar os pressupostos de senso comum e as estratégias retóricas - implícitas ou não - presentes nos textos. As práticas discursivas revelam tendências específicas, e algumas vezes contraditórias, na relação entre linguagem, discurso e poder (FAIRCLOUGH, 2001). Através da análise do discurso cepalino é possível compreender as concepções de Educação que sustentam as suas recomendações que, por sua vez, têm sido convertidas em práticas políticas.

Há várias definições do conceito de discurso elaboradas de diversas perspectivas teóricas. O conceito de discurso que utilizo é o mesmo adotado por Fairclough; no entanto, para conhecer outras descrições, transcrevo, a seguir, a definição de Teun Van Dijk, reconhecido por sua relevância nos trabalhos sobre racismo, imigração e mídia na Europa e na América Latina, dentro do campo da ACD:

Debería entenderse 'discurso' como uma forma de uso lingüístico $y$, de una forma más general, como un tipo de interacción social, condicionada por la cognición y socialmente contextualizada por los participantes, tomados como miembros sociales en situaciones sociales. El discurso, ya sea oral o escrito, se define, pues, como un evento comunicativo de un tipo especial, estrechamente relacionado con otras actividades comunicativas no verbales (tales como los gestos o el tratamiento de la imagen) y otras prácticas semióticas de significado, de significación y con los usos sociales de códigos simbólicos, como los de la comunicación visual (por ejemplo, los grá- ficos, la fotografía o el cine). Estas sucintas definiciones de discurso ya sugieren múltiples relaciones con la cognición y con la sociedad. Así, hoy se acepta comúnmente que más que decir que el discurso 'tiene' significados, hay que afirmar que los usuarios de las lenguas le 'asignan' significados. Estas asignaciones, tradicionalmente llamadas 'interpretaciones', son de naturaleza a la vez cognitiva y social (VAN DIJK, 1997, p. 68-69).

Diane Macdonell, citada por Fairclough (2001), em seu estudo althusseriano intitulado Theories of discourse an introduction afirma que "todos os 
discursos são ideologicamente posicionados; nenhum é neutro "(MACDONELL, 1986, p.59). Para Fairclough ${ }^{5}$, o discurso ao mesmo tempo em que é moldado pela estrutura social também Ihe é constitutivo. A análise faircloughiana aborda os conceitos de linguagem e de globalização a partir de quatro referências: (a) objetivista - que compreende a globalização como um fato objetivo, no qual o discurso tanto pode representar quanto pode se omitir dessa função; (b) retoricista - a forma como os discursos da globalização são utilizados sobre determinado assunto; (c) ideologicista - a maneira como os discursos da globalização podem contribuir para legitimar uma ordem estabelecida, a qual incorpora assimetricamente as relações de poder que ocorrem entre e dentro de diversos países; e, (d) construtivista social - o discurso com significantes efeitos causais no processo de construção social.

A abordagem faircloughiana considera discurso como forma de prática social ou a forma como as pessoas agem sobre o mundo e especialmente sobre os outros, como também um modo de representação. Para Fairclough (2001) a linguagem como prática social requer um modo de compreensão historicamente situado, dentro de uma construção social e constituído de identidades sociais, relações sociais e sistemas de conhecimento e crença.

Reporto-me, também, aos aspectos que levam Fairclough a pensar a linguagem mercadológica no contexto educacional. Nos termos do autor, "um aspecto da mudança discursiva com constituição metafórica da educação e de outros serviços como mercados é um elemento potente na transformação não apenas do discurso, mas também do pensamento e da prática nessas esferas" (FAIRCLOUGH, 2001, p. 241).

Para Fairclough (2001), a análise do discurso deve focalizar "a variabilidade, a mudança e a luta: variabilidade entre as práticas e heterogeneidade entre elas como reflexo sincrônico de processos de mudança histórica que são moldados pela luta entre as forças sociais" (p. 58-59).

Os efeitos do discurso estão relacionados às três funções da linguagem: identitária - "modos pelos quais as identidades sociais são estabelecidas no discurso"; relacional - "como as relações sociais entre os participantes do discurso são representadas e negociadas"; e ideacional - "modos pelos quais os

\footnotetext{
${ }^{5}$ Op. Cit.
} 
textos significam o mundo e seus processos, entidades e relações" (FAIRCLOUGH, 2001, p.92).

\section{Considerações finais}

A abordagem de Fairclough (2001) implica em uma relação dialética entre o discurso e a estrutura social. Discurso como prática, não apenas de representação do mundo, mas de significação do mundo, constituindo $e$ construindo o mundo em significado (p.91). A teoria de Fairclough (2001) tem como objetivo desenvolver uma análise do discurso capaz de investigar a mudança na linguagem como um método de estudo das mudanças sociais e culturais. E, ainda, tem como objetivo contribuir para "o desenvolvimento de um modelo hegemônico da prática discursiva, especialmente em oposição ao modelo de código predominante" (p. 273).

Fairclough (2001) apresenta um modelo tridimensional de análise, cujos elementos se constituem de três níveis - os aspectos estruturais de textos, práticas discursivas e práticas sociais. Além disso, os textos produzem efeitos sobre as pessoas, e tais efeitos são determinados pela relação dialética entre texto e contexto social (idem). O ponto que destaco é que o uso intensivo das TIC tem se constituído, fundamentalmente, "como as grandes vias de 'democratização' das informações e do conhecimento em tempo real, representando interesses estratégicos para o capital" (LIMA, 2011, p.02).

Em um acesso ${ }^{6}$ a página do Repositório Digital da CEPAL para buscar as ocorrências de publicações que contenham a expressão "Educação e Tecnologia" encontro 3.4780 itens agrupados nas categorias livros, artigos, documentos de conferência e reuniões, publicações em periódicos, revistas e boletins. $\mathrm{Na}$ segunda tentativa, na mesma data de acesso, alterei o descritor da pesquisa para "Educação" e as ocorrências se limitaram a 994 itens agrupados nas mesmas categorias anteriormente descritas.

Em síntese, é preciso mencionar que nos documentos orientadores da CEPAL, a integração das TIC na Educação na América Latina e Caribe tem sido

${ }^{6}$ Fonte:<http://repositorio.cepal.org/discover?scope=\%2F\&query=tecnologia++e+educa\%C3\%A7\% C3\%A3o\&submit=Ir> Acesso no dia 14 jan. 2017.

TrabalhoNecessario - www.uff.br/trabalhonecessario; Ano 15, № 27/2017 
realizada através de políticas educacionais, principalmente por meio de programas e projetos, que buscam "facilitar a inclusão social e a universalização dos direitos da cidadania" (CEPAL, 2010).

No entanto, no caso do Brasil, a formação docente tem sido, reconhecidamente, insatisfatória no que se refere à integração das TIC nos atos de currículo, o que inviabiliza avanços significativos em direção a uma efetiva utilização destas ferramentas como estratégias de ensino e aprendizagem.

\section{REFERÊNCIAS}

BARRETO, R. G.; LEHER, R. Do discurso e das condicionalidades do Banco Mundial, a educação superior "emerge" terciária. Revista Brasileira de Educação, n. 39, p. 423-436, set. /dez. 2008.

BARRETO, Raquel Goulart. Discursos, tecnologias, educação. Rio de Janeiro: EDUERJ, 2009.

BIELCHOWSKY, Ricardo. Cinquenta anos de pensamento na CEPAL - Uma resenha. In: BIELCHOWSKY, Ricardo (Org.). Cinquenta anos de Pensamento na Cepal. Rio de Janeiro: Record, 2000.

CEPAL. Comisión Económica para América Latina y el Caribe. Transformación productiva con equidad: la tarea prioritaria del desarrollo de América Latina y el Caribe en los años noventa. Santiago de Chile: CEPAL, 1990.

CEPAL. Comisión Económica para América Latina y el Caribe. Educación y conocimiento: eje de la transformación productiva con equidad/ Ernesto Ottone. Santiago de Chile, agosto de 1995.

CEPAL. Comisión Económica para América Latina y el Caribe. Invertir mejor para invertir más: Financiamiento y Gestión de la Educación en América Latina y el Caribe. Santiago, Chile, 2005.

CEPAL. Comisión Económica para América Latina y el Caribe. Programa de conectividade do século XXI. 2015. Disponível em:

$<$ http://www.cisco.com/c/pt_br/solutions/industries/education.html> Acesso 02 set 2016.

CEPAL. Comisión Económica para América Latina y el Caribe. Benefícios da Digitalização da Educação para a América Latina. 2016 Disponível em: <https://www.caf.com/pt/presente/noticias/2016/05/caf-cepal-e-cisco-juntamesforcos-para-digitalizar-a-educacao-na-america-latina/> Acesso em 01 jan 2017. 
CEPAL. Comisión Económica para América Latina y el Caribe. La nueva revolución digital: de la internet del consumo a la internet de la producción. Santiago: CEPAL, 2016.

FAIRCLOUGH, Norman. Language and power. New York: Longman, 1989.

FAIRCLOUGH, Norman. Discurso e mudança social. Brasília: Editora Universidade de Brasília, 2001.

FAIRCLOUGH, Norman. Language and Globalization. London: Routledge, 2006.

GENTILI, Pablo. A falsificação do consenso: simulacro e imposição na reforma educacional do Neoliberalismo. Vozes: Petrópolis, 2001.

KRUPPA, Sônia Maria Portela. O Banco Mundial e as Políticas de Educação nos anos 90. 2000. 382 f. Tese (Doutorado em Educação) - Faculdade de Educação da Universidade de São Paulo, São Paulo, 2000.

LEHER, Roberto. Para fazer frente ao apartheid educacional imposto pelo Banco Mundial: notas para uma leitura da temática trabalho-educação. Trabalho e Crítica. Anuário do GT Trabalho e Educação da ANPEd. EDUFF/NETE-UFMG, set. 1999a.

LEHER, Roberto. Um Novo Senhor da Educação? A política educacional do Banco Mundial para a periferia do capitalismo. Outubro, São Paulo, v. 1, n. 3, p. 19-30, 1999b.

LEHER, R. 25 anos de educação pública: notas para um balanço do período. In: GUIMARÃES, C. (org.), BRASIL, I. \& MOROSINI, M. V. Trabalho, Educação e Saúde: 25 anos de formação politécnica no SUS. Rio de Janeiro: EPSJV, $2010 \mathrm{~b}$.

LIMA, Kátia Regina de Souza. Organismos internacionais: o capital em busca de novos campos de exploração. In: NEVES, Maria Lúcia Wanderley (org.). O empresariamento da educação; novos contornos do ensino superior no Brasil dos anos 1990. Rio de Janeiro: Xamã, 2001.

LIMA, Kátia Regina de Souza. Organismos internacionais e política de educação superior na periferia do capitalismo. Texto apresentado no GT 11 - Políticas da Educação Superior na 26 ${ }^{\mathrm{a}}$ Reunião Anual da ANPEd, realizada em Poços de Caldas de 5 a 8 de outubro de 2003.

MACDONELL, Diane. Theories of discourse: an introduction. Oxford: Basil Blackwell, 1986.

NORTH, Douglass C. Institutions, institutional change and economic performance. New York: Cambridge University Press, 1991.

SGUISSARDI, Valdemar. Reforma Universitária no Brasil - 1995-2006: precária trajetória e incerto futuro. Revista Educação \& Sociedade, Campinas, v. 27, n. 96, pp. 1021-1056, 2006. 
VAN DIJK, Teun. Discurso, cognición y sociedad. Signos. Teoría y práctica de lo educación. Octubre-Diciembre de 1997. p. 66-74.

Recebido em: 31 de janeiro de 2017 Aprovado em: 08 de outubro de 2017 Publicado em: 5 de dezembro de 2017 